\title{
NATURAL FIBER REINFORCED COMPOSITES: A REVIEW ON POTENTIAL FOR CORRUGATED CORE OF SANDWICH STRUCTURES
}

\author{
A.F. Jusoh ${ }^{1, a}$, M.R.M. Rejab ${ }^{1}$, J.P Siregar ${ }^{1}$, D. Bachtiar ${ }^{1}$ \\ ${ }^{1}$ Faculty of Mechanical Engineering, Universiti Malaysia Pahang 26600 Pekan, Pahang, Malaysia
}

\begin{abstract}
Natural fibers, characterized by sustainability, have gained a considerable attention in recent years, due to their advantages of environmental acceptability and commercial viability. In this paper, the characterization of natural fibers including the mechanical properties and alkalization of fibers is presented. Most recent study had gone through the mercerization process to improve the toughness of natural fibers; which is a well-known hydrophilic material. Traditional reinforcement method was commonly used to fabricate a natural fiber composite such as hand lay-up and mold press due to its convenience in terms of time and cost. Also, different kind of matrix material used in different kind of natural fibers gave high impact on the tensile and flexural test result. By selecting appropriate chemical treatment, matrix material and fabrication method, the tensile and flexural test gives different results and findings. As most researchers tend to use metals to create corrugated cores for sandwich structure, it is possible to develop this structure using natural fibers such as kenaf, wood dust, and other natural fibers.
\end{abstract}

\section{Introduction}

Natural fiber encircle all forms of fiber from grasses, seeds, woody plants, fruits, wild plants, agriculture crops, water plants, palms, leaves, animal feathers and its skins. By-products such as banana, pineapple, sugarcane, sugar palm, rice, cotton, coconut, kenaf, hemp, abaca, sisal, oil palm, jute and bamboo are very well known to produce composites [1]. Natural fibers can also be classified into certain fiber categories such as bast, leaf, seed, fruit, grasses, reeds and woods as in figure 1. Some of the advantages of natural fibers are very environmentally friendly, fully biodegradable, a non-toxic material and sources of income for rural and agricultural community.

There are disadvantages for natural fibers such as poor compatibility with hydrophobic polymer matrix. These drawbacks need several treatments to improve compatibility, such as alkali treatment and coupling agent [2]. Moreover, alkali treatment increased the mechanical properties of the composites itself, resulting improved surface wettability of the fiber against the matrix $[3,4]$.
On the other hand, sandwich structures with various types of cores are widely used in aerospace, high-speed train, civil engineering and so on. The structures have becoming quite familiar and famous in manufacturing nowadays due to its properties of lightweight and high stiffness [5]. Many researchers have focused on the dynamic mechanical behavior of sandwich structures with corrugated cores. A variety of such structure of different metallic cores including stochastic foams, honeycombs, prismatic topologies, and lattice topologies have been investigated experimentally and numerically [6-8]. Between all sandwich structures, desirable solutions are the corrugated cores. The characteristic of corrugated core is providing good structural performance with very restricted thickness in total and small thickness compared to overall measurement which affect negatively of their modeling [9]. Most researchers were using metallic cores, stochastic foams, honeycombs, lightweight ceramic and polymeric foams to study the characteristic and the effect of sandwich panel with corrugated cores [10-14].

\footnotetext{
$\overline{{ }^{a} \text { Corresponding author: fahmyjusoh } @ g m a i l . c o m ~}$
} 


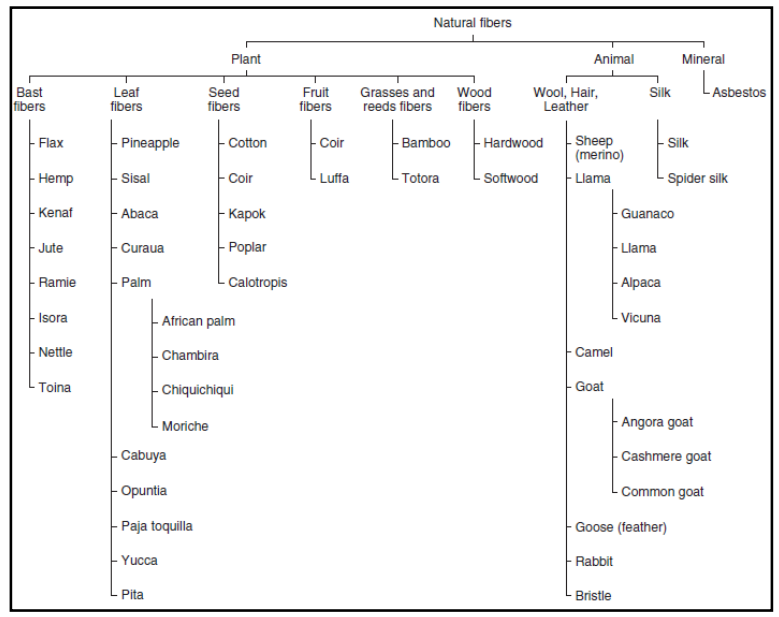

Figure 1. The classification of natural fiber [15].

\section{Kenaf Fiber Composite}

Kenaf was found to be comparative, much available and cheapest amongst other types of natural fiber reinforced material. Kenaf also labeled as industrial kenaf due to its great returns in manufacturing of industrial raw materials.

Kenaf fiber comes from species of Hibiscus cannabinus where its subdivision is Hibiscus and family Malvaceae obtained from plant's stems [16] which also includes cotton (Gossypium spp.) and okra (Abelmoschus esculentus L. Moench). The word kenaf itself originated from Persian which describing the plant having warm season, short day, and annually herbaceous plant, with the fiber diameter is $67.6 \mu \mathrm{m}$ in average [17]. Kenaf is a tough, strong and hardy plant with a fibrous stalk, invulnerable to insect damages and needs relatively less of or no pesticides [18]. Kenaf fiber comprise of cellulose, hemicellulose, and lignin with the value of $56-$ $64,21-35$, and $8-14$ by weight percentage (Wt. \%) $[19,20]$.

A long history recorded that kenaf fiber's cultivation was practiced in some areas in the world such as Malaysia, Thailand, Bangladesh, India, parts of Africa and Europe. The fiber has been mainly used in paper, cloth, coarse, twine and rope. However in today's market there is demand for kenaf reinforced for polymers. As encouraged by the local government of Malaysia, planting, cultivating and harvesting of kenaf plant has growth widely in rural area in order to replace the tobacco plant as well as to support local market in producing high-density fiberboard and then exported the products worldwide. Also, kenaf fibers received a lot of attention to support for multi-application including automotive parts, packaging and furniture as well as sports and leisures [21].

There are many types of research with regards in application of kenaf fiber as main material throughout the characterization and its properties. Mahjoub, R. et al. [17] recorded the tensile properties and elastic modulus of kenaf fibers are $930 \mathrm{MPa}$ and $53 \mathrm{GPa}$, respectively. Compared to Mazuki, Davoodi and Summerscale et al. in Table 1, the tensile properties of kenaf is in range of 240 to $800 \mathrm{MPa}$ and its elastic modulus range from 14 to 60
GPa $[19,20,22]$. The authors were using kenaf fiber with almost same density but the types of kenaf must be taken into consideration either short or long kenaf. A factor that affects the properties of kenaf fiber is the matrix material used in the process. Salleh et al. [16] using Polyester with 100 to 20 by weight as its matrix material and done the process by hand lay-up. Meanwhile, Meon et al. [21] used Polyethylene and Polypropylene with maximum $67 \%$ by weight of matrix but fabricated with hot press moulding, compared to Vijayakumar et al. [23] who used $90 \%$ by weight of Epoxy and then fabricated with hand lay-up process.

Table 1. Mechanical properties of kenaf fiber composite.

\begin{tabular}{|c|c|c|c|c|}
\hline $\begin{array}{c}\text { Density } \\
\left(\mathbf{g} / \mathbf{c m}^{\mathbf{3}}\right)\end{array}$ & $\begin{array}{c}\text { Tensile } \\
\text { Strength } \\
\mathbf{( M P a )}\end{array}$ & $\begin{array}{c}\text { Elastic } \\
\text { Modulus } \\
\mathbf{( G P a )}\end{array}$ & $\begin{array}{c}\text { Elongation } \\
\text { at break } \\
\mathbf{( \% )}\end{array}$ & Ref. \\
\hline 1.44 & $393-773$ & 26.5 & $1.5-1.8$ & {$[19]$} \\
\hline 1.4 & $284-800$ & $21-60$ & 1.6 & {$[20]$} \\
\hline 1.193 & $240-600$ & $14-38$ & & {$[22]$} \\
\hline
\end{tabular}

\section{BANANA, HEMP, WOOD DUST, AND JUTE FIBERS}

Other selective natural fibers where some researchers used in determining its mechanical properties as in Table 2 are banana, hemp, wood dust, and jute. Gosh et al. [24] treated its banana fibers with $5 \%$ of $\mathrm{NaOH}$ and dried the banana fiber mat in $80^{\circ} \mathrm{C}$ for 24 hours, the same method used by Meon. The matrix material used for his experiment is Bisphenol Epoxy based and Vinyl Ester, fabricated using hand lay-up technique and the tensile properties is $122 \mathrm{MPa}$. Singh et al. [25] used hemp fibers in their study of tensile and flexural which gives a result of 17.39 MPa and 16.39 MPa for both tensile and flexural test respectively. The hemp fibers were mixed with $90 \%$ High Density Polyethylene (HDPE) and fabricated with injection molding machine after gone through mercerization process of $5 \% \mathrm{NaOH}$ in 24 hours.

For wood dust fiber, Kumar et al. [26] managed to get the maximum of $28.29 \mathrm{MPa}$ and $1335.20 \mathrm{MPa}$ of tensile and flexural strength which through $15 \%$ of Epoxy and Hardener using glass vacuum chamber as its fabrication method. But then, Kumar did not mention any mercerization process in the making of his composite material testing. The same goes to Mishra et al. [27] who study the mechanical properties of jute composed with Epoxy. However, Mishra recorded a $110 \mathrm{MPa}$ and 55.8 $\mathrm{MPa}$ of tensile and flexural strength which is the results is higher than recorded by Singh for hemp fibers even though Mishra did not execute any mercerization process to his fibers. 
Table 2. Other selective natural fibers reinforced composite.

\begin{tabular}{|l|l|l|l|c|}
\hline Fiber & $\begin{array}{l}\text { Matrix } \\
\text { Material }\end{array}$ & $\begin{array}{l}\text { Resin } \\
\text { Comp. }\end{array}$ & Fabrication & Ref. \\
\hline Kenaf & $\begin{array}{l}\text { Polyethylene } \\
\text { \& } \\
\text { Polypropylen } \\
\text { e }\end{array}$ & $\begin{array}{l}30,67,3 \\
\mathrm{wt} \%\end{array}$ & $\begin{array}{l}\text { Hot press } \\
\text { molding }\end{array}$ & {$[21]$} \\
\hline Kenaf & Epoxy & $90 \%$ & Hand lay-up & {$[23]$} \\
\hline Banana & $\begin{array}{l}\text { Bisphenol } \\
\text { epoxy based } \\
\text { Vinyl ester }\end{array}$ & - & Hand lay-up & {$[24]$} \\
\hline Hemp & $\begin{array}{l}\text { High Density } \\
\text { Polyethylene } \\
\text { HDPE }\end{array}$ & $\begin{array}{l}70 \%, \\
80 \%, \\
90 \%\end{array}$ & $\begin{array}{l}\text { Injection } \\
\text { molding }\end{array}$ & {$[25]$} \\
\hline $\begin{array}{l}\text { Wood } \\
\text { Dust }\end{array}$ & $\begin{array}{l}\text { Epoxy }+ \\
\text { Hardener } \\
(10: 8)\end{array}$ & $\begin{array}{l}0,2.5,5, \\
7.5,10, \\
12.5,15 \\
(\mathrm{wt} \%)\end{array}$ & $\begin{array}{l}\text { Vacuum } \\
\text { glass } \\
\text { chamber }\end{array}$ & {$[26]$} \\
\hline Jute & Epoxy & $\begin{array}{l}100,88, \\
76,64, \\
52\end{array}$ & Hand lay-up & {$[27]$} \\
& & $\mathrm{wt} \%)$ & & \\
\hline
\end{tabular}

\section{Mercerization of Fibers}

Another factor which affects the properties of kenaf is the mercerization process. Treating the fibers with Sodium Hydroxide $(\mathrm{NaOH})$ also known as mercerization process helps in mending the interfacial bonding between the resin and fiber ensuing better mechanical properties. Several authors state that mechanical properties of fiber composites can be improved by chemically treating the fibers. It is well known that alkaline treatment is to clean the fiber surface off its impurities, modifies the surface structure and increase the fiber surface area. The moisture absorption by the fiber composites and its detrimental effect on the mechanical properties are a prime concern especially when these are used in marine application [24]. As an example, Meon and Vijayakumar did the mercerization process whereby the fibers were diluted and washed in $\mathrm{NaOH}$ solution in 4 to 24 hours and then dried in the fibers for the next couple days. As results, Meon recorded up to $15 \mathrm{MPa}$ and $18 \mathrm{MPa}$ for tensile and flexural strength but Vijayakumar managed to record higher which approximately $25 \mathrm{MPa}$ and $35 \mathrm{MPa}$ after both experimental gone through mercerization process.

However, there are disadvantages of natural fiber reinforced composites such as inadequate adhesion, poor wettability; high level of moisture absorption, and debonding but the alkali treatment of fibers significantly reduces these drawbacks. In order to increase elastic modulus of fiber by increasing molecular orientation, the alkali treatment needed to reduce the spiral angle by removing the lignin and hemicellulose content in the fiber. Also, to improve the mechanical properties of fibers, the improvement of interfacial bonding is crucial. The alkali treatment provides superior bonding, defects reduction, reduced moisture absorption, increasing crystallinity and finer fabric [28]. High moisture absorption and weak adhesion to hydrophobic matrices was resulted from the hydrophilicity of natural fibers.
This set of drawback can be treated to improve and to increase the adhesion to matrix material [29].

Natural fibers also inherent high moisture absorption and it need to be removed by drying or conditioned before use. By removing or controlling moisture content, voids and poor fiber-matrix adhesion can be avoided. In addition, by applying more heat during production of composites could be enough to remove moisture. Rassman, et al. [30] found that by loading fibers into a preheated mold, placing the mold in the oven and drawing warm air through it can reduce moisture absorption but not all fibers could be dried in this method. Significant amount of moisture did not absorb when the fibers were dried in the oven and then sealed inside the mold for $2 \mathrm{~min}$. Ramesh et al. [31] controlling the moisture content by drying the fibers under hot sun for 24 hours, compared to Srinivasababu et al. [32] who dried the fibers at ambient conditions until the moisture is removed by natural means. Boopathi et al. [33] dried the natural fibers with sunlight for only 3 to 5 hours and typically it depends on what fibers were used. However, the needs of mercerization and proper matrix material selected should impact the results of its mechanical properties. The results from each researcher are different as the purpose of study is differing.

\section{Potential of Natural Fiber for Corrugated Cores}

Corrugated core are a subset of two-dimensional periodic cores and most important feature is the corrugation shape, that can be varied for a fabricated design of the components [9]. A lot of theoretical, numerical, and experimental studies have been conducted to find its failure mode, properties of the design and the behavioral of corrugated core sandwich structure [6, 9-14, 34-37]. In Figure 2, Buannic et al. [35] reported that corrugated core sandwich structure can be categorized into four different conventional geometries; straight, hat-type, triangular and curvilinear. Then, comparison of the properties of these four geometries to a reference stiffened panel was made by the authors. The purpose of this comparison is to determine the pure bending characteristic of periodic plates and equivalent membrane.

Figure 2. Traditional corrugated core sandwich structure [35].
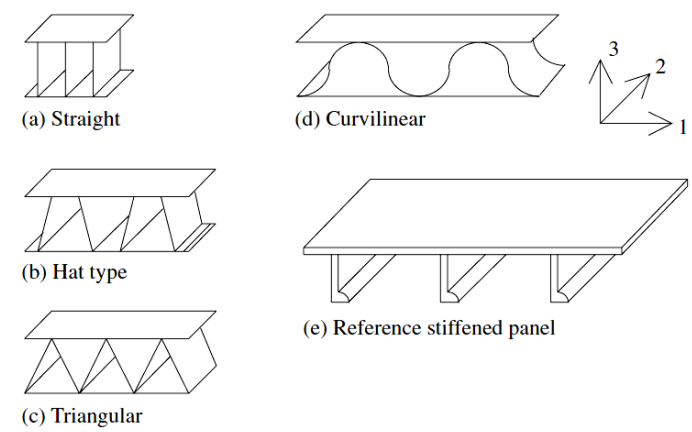

(e) Reference stiffened panel

(c) Triangular

As in previous chapter, most researches uses sheet metal as such Bartolozzi et al. [9, 34] did reported the 
use of metal due to its main characteristic which is high stiffness-to-mass ratio, most likely under bending conditions. Zhang et al. [6, 10, 14] and Lim et al. [13] used stainless steel sheet to study the dynamic and buckling response of trapezoidal corrugated core sandwich structure panels. As compared to Yan et al. [12], the authors discussed more on bending points of sandwich beams using aluminum foam-filled and found out that foam insertions altered not only the failure mode of the corrugated sandwich but also increased dramatically its bending resistance. At this point, researchers tend to use metal in terms of sheets or foams and disregard the potential of natural fiber reinforced composite to replace the material use in experimental work even though that Wei et al. [11] was possible using $\mathrm{Zr} 02$ ceramic in studying of mechanical properties of corrugated core sandwich panel. Therefore, there are possibilities of using natural fiber reinforced composite to produce corrugated core sandwich structure and more studies need to be done to replace current material.

\section{Conclusion}

On top of all experimental disclosed in the literature, none authors fabricated a corrugated core sandwich structure using natural fibers. As most authors tend to use metals, it is possible to develop this structure using natural fibers such as kenaf, wood dust, and other natural fibers. Researchers may run several testing to study the characterization of corrugated core sandwich structure using only natural fiber reinforced composite. This is the gap in research field that require more experimental work to be done using natural fiber reinforced composite to fabricate corrugated core sandwich structure.

Also, different kind of matrix material used in different kind of natural fibers did gave an impact on the tensile and flexural test result. By selecting appropriate chemical treatment, matrix material and fabrication method, the tensile and flexural test gives different results and findings.

\section{Acknowledgement}

The authors are grateful to the Ministry of Education for funding this research (FRGS/1/2014/TK01/UMP/02/3).

\section{References}

1. Salit, M.S., Tropical Natural Fiber Composite; Properties, Manufacture and Applications. 2014. 1.

2. Goulart, S.A.S., et al., Mechanical Behaviour of Polypropylene Reinforced Palm Fibers Composites. Procedia Engineering, 2011. 10: p. 2034-2039.

3. Fiore, V., G. Di Bella, and A. Valenza, The effect of alkaline treatment on mechanical properties of kenaf fibers and their epoxy composites. Composites Part B: Engineering, 2015. 68: p. 14-21.

4. Nirmal, U., J. Hashim, and M.M.H. Megat Ahmad, A review on tribological performance of natural fibre polymeric composites. Tribology International, 2015. 83: p. 77-104.

5. Wu, Z.-J., F.-M. Li, and Y.-Z. Wang, Vibration band gap behaviors of sandwich panels with corrugated cores. Computers \& Structures, 2013. 129: p. 30-39.

6. Zhang, P., et al., Experimental and numerical investigations on laser-welded corrugated-core sandwich panels subjected to air blast loading. Marine Structures, 2015. 40: p. 225-246.

7. Rejab, M. and W. Cantwell, The mechanical behaviour of corrugated-core sandwich panels. Composites Part B: Engineering, 2013. 47: p. 267-277.

8. Rejab, M., K. Ushijima, and W. Cantwell, The shear response of lightweight corrugated core structures. Journal of Composite Materials, 2013: p. 0021998313514086.

9. Bartolozzi, G., N. Baldanzini, and M. Pierini, Equivalent properties for corrugated cores of sandwich structures: A general analytical method. Composite Structures, 2014. 108: p. 736-746.

10. Zhang, J., et al., Improving the bending strength and energy absorption of corrugated sandwich composite structure. Materials \& Design, 2013. 52: p. 767-773.

11. Wei, K., et al., Fabrication and mechanical properties of lightweight $\mathrm{ZrO} 2$ ceramic corrugated core sandwich panels. Materials \& Design, 2014. 64: p. 91-95.

12. Yan, L.L., et al., Three-point bending of sandwich beams with aluminum foam-filled corrugated cores. Materials \& Design, 2014. 60: p. 510-519.

13. Lim, J.-Y. and H. Bart-Smith, Theoretical approach on the dynamic global buckling response of metallic corrugated core sandwich columns. International Journal of Non-Linear Mechanics, 2014. 65: p. 14-31.

14. Zhang, P., et al., Dynamic response of metallic trapezoidal corrugated-core sandwich panels subjected to air blast loading - An experimental study. Materials \& Design, 2015. 65: p. 221-230.

15. L. Nicolais, A.B., Wiley Encyclopedia of Composites - Natural Fibres. 2012. 5 Vol Set 2nd Ed.

16. Salleh, Z., et al., Fracture Toughness Investigation on Long Kenaf/Woven Glass Hybrid Composite Due To Water Absorption Effect. Procedia Engineering, 2012. 41: p. 16671673.

17. Mahjoub, R., et al., Tensile properties of kenaf fiber due to various conditions of chemical fiber surface modifications. Construction and Building Materials, 2014. 55: p. 103-113. 
18. Elsaid, A., et al., Mechanical properties of kenaf fiber reinforced concrete. Construction and Building Materials, 2011. 25(4): p. 1991-2001.

19. Mazuki, A.A.M., et al., Degradation of dynamic mechanical properties of pultruded kenaf fiber reinforced composites after immersion in various solutions. Composites Part B: Engineering, 2011. 42(1): p. 71-76.

20. Davoodi, M.M., et al., Mechanical properties of hybrid kenaf/glass reinforced epoxy composite for passenger car bumper beam. Materials \& Design, 2010. 31(10): p. 4927-4932.

21. Meon, M.S., et al., Improving Tensile Properties of Kenaf Fibers Treated with Sodium Hydroxide. Procedia Engineering, 2012. 41: p. 1587-1592.

22. Summerscales, J., et al., A review of bast fibres and their composites. Part 1 - Fibres as reinforcements. Composites Part A: Applied Science and Manufacturing, 2010. 41(10): p. 1329-1335.

23. Vijayakumar, S., et al., Mechanical and Microstructure Characterization of Coconut Spathe Fibers and Kenaf Bast Fibers Reinforced Epoxy Polymer Matrix Composites. Procedia Materials Science, 2014. 5: p. 2330-2337.

24. Ghosh, R., et al., Water Absorption Kinetics and Mechanical Properties of Ultrasonic Treated Banana Fiber Reinforced-vinyl Ester Composites. Procedia Materials Science, 2014. 5: p. 311-315.

25. Singh, S., et al., Tensile and Flexural Behavior of Hemp Fiber Reinforced Virgin-recycled HDPE Matrix Composites. Procedia Materials Science, 2014. 6: p. 1696-1702.

26. Kumar, R., et al., Study of Mechanical Properties of Wood Dust Reinforced Epoxy Composite. Procedia Materials Science, 2014. 6: p. 551-556.

27. Mishra, V. and S. Biswas, Physical and Mechanical Properties of Bi-directional Jute Fiber Epoxy Composites. Procedia Engineering, 2013. 51: p. 561-566.

28. Prasad, V., et al., Finite Element Analysis of Jute and Banana Fibre Reinforced Hybrid Polymer Matrix Composite and Optimization of Design Parameters Using ANOVA Technique. Procedia Engineering, 2014. 97: p. 1116-1125.

29. Sgriccia, N., M.C. Hawley, and M. Misra, Characterization of natural fiber surfaces and natural fiber composites. Composites Part A: Applied Science and Manufacturing, 2008. 39(10): p. 1632-1637.

30. Rassmann, S., R.G. Reid, and R. Paskaramoorthy, Effects of processing conditions on the mechanical and water absorption properties of resin transfer moulded kenaf fibre reinforced polyester composite laminates. Composites Part A: Applied Science and Manufacturing, 2010. 41(11): p. 1612-1619.

31. Ramesh, M., et al., Processing and Mechanical Property Evaluation of Banana Fiber
Reinforced Polymer Composites. Procedia Engineering, 2014. 97: p. 563-572.

32. Srinivasababu, N., J.S. Kumar, and K.V.K. Reddy, Manufacturing and Characterization of Long Palmyra Palm/Borassus Flabellifer Petiole Fibre Reinforced Polyester Composites. Procedia Technology, 2014. 14: p. 252-259.

33. Bhoopathi, R., M. Ramesh, and C. Deepa, Fabrication and Property Evaluation of Banana-Hemp-Glass Fiber Reinforced Composites. Procedia Engineering, 2014. 97: p. 2032-2041.

34. Bartolozzi, G., et al., An equivalent material formulation for sinusoidal corrugated cores of structural sandwich panels. Composite Structures, 2013. 100: p. 173-185.

35. Buannic, N., P. Cartraud, and T. Quesnel, Homogenization of corrugated core sandwich panels. Composite Structures, 2003. 59(3): p. 299-312.

36. Liu, P., Y. Liu, and X. Zhang, Internalstructure-model based simulation research of shielding properties of honeycomb sandwich panel subjected to high-velocity impact. International Journal of Impact Engineering, 2015. 77: p. 120-133.

37. Magnucka-Blandzi, E., K. Magnucki, and L. Wittenbeck, Mathematical modeling of shearing effect for sandwich beams with sinusoidal corrugated cores. Applied Mathematical Modelling, 2015. 39(9): p. 2796-2808. 